DOI: 10.12957/demetra.2016.15053

\title{
Culinária regional, nacional ou global: uma revisão narrativa do manifesto regionalista de 1926 escrito por Gilberto Freyre
}

\section{Regional, national or global cooking: a narrative review of the manifesto regionalista of 1926 written by Gilberto Freyre}

Francisco de Assis Guedes de

Vasconcelos'

Universidade Federal de Santa Catarina, Centro de Ciências da Saúde, Departamento de Nutrição. Florianópolis-SC, Brasil.

Correspondência / Corrrespondence

Francisco de Assis Guedes de Vasconcelos

E-mail: f.vasconcelos@ufsc.br

\section{Resumo}

O artigo tem por objetivo analisar a contribuição de Gilberto Freyre no debate intelectual das décadas de 1920 e 1930 sobre a construção da identidade nacional, tomando como foco de análise sua abordagem da centralidade da culinária regional no processo identitário da sociedade brasileira, contida no livro Manifesto Regionalista, de 1926. O Manifesto foi divulgado no Primeiro Congresso Regionalista, realizado em fevereiro de 1926, no Recife, em contraposição à Semana de Arte Moderna de 1922, ocorrida em São Paulo. No livro, Freyre discute os conceitos de regionalismo, nacionalismo, internacionalismo, entre outros; descreve os valores tradicionais da cultura nordestina; identifica as ameaças a que estes estavam submetidos e propõe estratégias para sua valorização. Entre os valores culturais enaltecidos, destacam-se aspectos da arquitetura e da culinária regional. A revisão chama a atenção para o pioneirismo das estratégias recomendadas para a preservação da cozinha nordestina, considerada por Freyre aquela que melhor expressava o sincretismo das cozinhas das três raças (ameríndia, portuguesa e africana). A análise aponta semelhanças entre o Manifesto e a segunda edição do Guia Alimentar para a População Brasileira, enfatizando a atualidade da abordagem de Freyre. Ambos adotam pressupostos conservadores, ancorados na valorização do passado (tradições) e na hostilidade para com as transformações (modernidade): no Manifesto, a defesa da culinária regional agráriopatriarcal nordestina e a hostilidade com a culinária estrangeira; no Guia, a valorização da culinária doméstica baseada em alimentos in natura e a hostilidade para com os alimentos ultraprocessados.

Palavras-chave: Culinária Regional; Culinária Brasileira; Manifesto Regionalista; Guia Alimentar; Alimentação e Nutrição; Gilberto Freyre. 


\section{Abstract}

The article aims to analyze the contribution of Gilberto Freyre for the intellectual debate of the 1920s and 1930s on the construction of national identity, focusing on the centrality of regional cooking in the identity process of the Brazilian society, according to the book Manifesto Regionalista, issued in 1926. The Manifesto was published in the First Regionalist Congress in February 1926, in Recife, Pernambuco state, as opposed to the 1922 Modern Art Week, held in São Paulo state, Brazil. In the book Freyre discusses the concepts of regionalism, nationalism, internationalism, among others; describes the traditional values of northeastern culture; identifies the threats to which they were submitted and proposes strategies for recovery. Among the exalted cultural values stand out aspects of architecture and regional cooking. The review draws attention to the pioneering spirit of the recommended strategies for the preservation of the northeastern cooking, considered by Freyre the one that best expressed the syncretism of the cuisines of the three races (American Indian, Portuguese and African). The analysis points to similarities between the Manifesto and the second edition of the Food Guide for the Brazilian Population, emphasizing the update of Freyre's approach. Both embrace conservative assumptions, anchored in the appreciation of the past (traditions) and hostility to the transformations (modernity): in the Manifesto, the defense of the northeastern agrarian-patriarchal regional cooking and the hostility to foreign cooking; in the Guide, the appreciation of the domestic cooking based on food in its natural state and hostility towards ultra-processed products.

Key words: Regional Cooking; Brazilian Cuisine; Manifesto Regionalista; Food Guide; Food and nutrition; Gilberto Freyre.

\section{INTRODUÇÃO}

A partir das duas últimas décadas do século XX, com o advento de fenômenos conhecidos como globalização econômica, ${ }^{1-4}$ transição demográfica/epidemiológica/alimentar/nutricional ${ }^{5-6}$ e o avanço da obesidade e outras doenças crônicas não transmissíveis a ela associadas, ${ }^{7}$ tem-se observado no contexto mundial e no Brasil, tanto no espaço acadêmico-científico como em outros espaços sociais, um relevante movimento que procura discutir e resgatar a valorização da culinária e/ou das tradições culinárias. ${ }^{8-18}$ 
No Brasil, instrumentos de políticas públicas de alimentação e nutrição e de promoção da saúde, divulgados nos últimos anos, também têm enfatizado a relevância e recomendado a adoção de práticas e habilidades culinárias no cotidiano das pessoas como estratégias de reeducação alimentar e nutricional e adoção de estilos de vida saudáveis. Um desses instrumentos é o Marco de Referência de Educação Alimentar e Nutricional para as Políticas Públicas, publicado em 2012. Entre os princípios estabelecidos para a realização de ações de educação alimentar e nutricional (EAN), o documento define a valorização da culinária enquanto prática emancipatória para a garantia da alimentação saudável (princípio IV, p. 26). ${ }^{19}$

Outro instrumento, publicado no final de 2014, é a segunda edição do Guia Alimentar para a População Brasileira, que no capítulo quinto dedica uma seção para discutir a importância de as pessoas desenvolverem habilidades culinárias como estratégia para a compreensão e a superação de obstáculos para a garantia da alimentação saudável (p. 103-124). ${ }^{20}$ Além disso, entre os Dez passos para uma alimentação adequada e saudável, a segunda edição do Guia Alimentar para a População Brasileira ${ }^{20}$ propõe como o sétimo passo "desenvolver, exercitar e partilhar habilidades culinárias", o qual é expresso da seguinte forma:

Se você tem habilidades culinárias, procure desenvolvê-las e partilhá-las, principalmente com crianças e jovens, sem distinção de gênero. Se você não tem habilidades culinárias - e isso vale para homens e mulheres -, procure adquiri-las. Para isso, converse com as pessoas que sabem cozinhar, peça receitas a familiares, amigos e colegas, leia livros, consulte a internet, eventualmente faça cursos e... comece a cozinhar! (p. 127).

Esse movimento contemporâneo que procura incentivar o ato de cozinhar ou o desenvolvimento de habilidades culinárias como estratégia para promover a alimentação adequada e saudável nos leva a revisitar o movimento de efervescência e debate intelectual das décadas de 1920 e 1930, em torno de reflexões sobre a formação da sociedade brasileira, com enfoque nos estudos de raça, clima, alimentação e construção da identidade nacional ou nacionalidade brasileira. ${ }^{21-25}$

Em estudo anterior, ao analisar a produção intelectual do sociólogo pernambucano Gilberto Freyre (1900-1987), publicada na década de 1930, particularmente o clássico Casa-grande e senzala ${ }^{26}$, Vasconcelos ${ }^{25}$ constatou que

[...] ao enfatizar o conceito de cultura na discussão sobre a valorização do povo brasileiro, Freyre tornou-se um dos principais interlocutores do debate travado, nas décadas de 1920 e 1930, entre distintas correntes intelectuais brasileiras, a respeito da construção de uma identidade nacional (p. 318).

Vasconcelos ${ }^{25}$ considerou Casa-grande e senzala ${ }^{26}$ o primeiro e mais completo ensaio sociológico sobre o padrão e os hábitos alimentares da sociedade brasileira (p. 318). Além disso, observou que a abordagem sociocultural sobre o processo de miscigenação defendido por Freyre encontrou

intima identificação no interior do movimento médico sanitário brasileiro que procurava afirmação das teses eugênicas, entre elas, a da valorização da raça brasileira (o mestiço) por meio de uma alimentação racional (p. 319). 
Este artigo tem por objetivo analisar a contribuição de Gilberto Freyre no debate intelectual das décadas de 1920 e 1930 sobre a construção da identidade nacional, tomando como foco de análise sua abordagem da centralidade da culinária regional no processo identitário da sociedade brasileira, contida na obra Manifesto Regionalista de $1926 .{ }^{27}$

\section{Notas iniciais sobre o Manifesto Regionalista de 1926}

O Manifesto Regionalista de 1926, segundo o próprio Freyre ${ }^{27}$ (p. 10-13), foi lido no Primeiro Congresso Regionalista, divulgado em parte por jornais da época (Diário de Pernambuco) e publicado pela primeira vez na íntegra, em 1952, pela Editora Região, após aquela realizada pelo Instituto Joaquim Nabuco de Pesquisa Social (atual Fundação Joaquim Nabuco), em 1953. No Manifesto Regionalista de $1926,{ }^{27}$ pela primeira vez no país, Freyre chamava a atenção para as ameaças de descaracterização da culinária regional e propunha algumas estratégias para valorização da estética e tradição da cozinha nordestina.

Ressalta-se que o Primeiro Congresso Regionalista, realizado em fevereiro de 1926, no Recife, organizado por Gilberto Freyre e seus pares, reuniu intelectuais, arquitetos, urbanistas, pintores e artistas pernambucanos e de outros estados brasileiros (Rio de Janeiro e São Paulo) com "o objetivo de discutir de forma ecológica e técnica a urbanização como problema regional”27 (p. 10). Surgiu, conforme algumas análises, ${ }^{28-30}$ em contraposição à Semana de Arte Moderna de 1922, ocorrida em São Paulo. Há indícios da similaridade entre o Manifesto Regionalista de $1926^{27}$ e o Manifesto Antropofágico, obra escrita em 1928 pelo escritor paulistano modernista Oswald de Andrade (1890-1954). ${ }^{30}$ Também há indícios de que o movimento regionalista iniciado em Recife com coparticipação ativa de Freyre tenha atraído intelectuais de distintos campos do conhecimento (antropologia, arquitetura, economia, história, sociologia, etc.) e influenciado a literatura regionalista de escritores como José Américo de Almeida, José Lins do Rego, Graciliano Ramos, Jorge Amado, Rachel de Queiroz, Érico Veríssimo, entre outros. ${ }^{27,29-32}$

O Manifesto já foi objeto específico de algumas análises, ${ }^{28-30}$ além de ter sido comentado/ referido em outra das distintas análises das obras de Freyre. ${ }^{33}$ As análises anteriores, a partir de distintos prismas metodológico-analíticos, já realizaram importantes interpretações do Manifesto, ${ }^{27}$ identificando os elementos centrais das matrizes teórica, filosófica, política e ideológica do pensamento freyreano contido nessa obra. ${ }^{28-30,33}$

Amaral Jr., ${ }^{28}$ por exemplo, procura demonstrar na análise que realizou das obras Manifest ${ }^{27}$ e Nordeste, ${ }^{32}$ que nelas Freyre procede a uma teorização/idealização do Nordeste, em contraposição à hegemonia do Sudeste nos dois principais contextos acadêmicos nos quais ele adquiriu notoriedade nacional: o modernismo nos anos 1920 e a institucionalização 
das ciências sociais brasileiras a partir dos anos 1930. O autor concluiu que a interpretação teórica de Freyre denota um conteúdo político-ideológico que foi sustentado por dois motivos românticos de idealização da Região Nordeste: o sonho da comunidade ideal e a hostilidade em relação à racionalidade burguesa ocidental (p. 227).

Por sua vez, a análise de Santos ${ }^{29}$ procurou identificar como o Manifesto ${ }^{27}$ se inseriu no debate sociocultural do campo intelectual dos anos 1920-1930, por meio de uma intervenção destacada nas discussões sobre o modernismo. Grosso modo, o autor concluiu que o Manifesto ${ }^{27}$ procurou realizar um resgate do passado rural colonial nordestino, estabelecendo um confronto entre tradição e modernidade, expressando uma estratégia relativamente conservadora de interpretação das transformações sociais.

A versão que usamos para realizar esta revisão do Manifest $0^{27}$ tem publicação datada de 1955 , sendo um texto composto por 54 páginas. Além do prefácio com três páginas, precede o corpo específico do Manifesto um texto introdutório com sete páginas, denominado "Vinte cinco anos depois". Este corresponde ao discurso proferido por Freyre na noite de 20 de março de 1951, em evento realizado pelo então Instituto Joaquim Nabuco de Pesquisa Social, em comemoração ao 25ํㅜ aniversário do Primeiro Congresso Regionalista. Portanto, o conteúdo específico do Manifesto ${ }^{27}$ compreende um conjunto de 44 páginas distribuídas em 21 seções.

Nas primeiras seções, Freyre introduz seus pressupostos teórico-conceituais e políticoideológicos, abordando os conceitos de regionalismo, nacionalismo, internacionalismo, federalismo, barrismo, separatismo, articulação inter-regional, entre outros, para em seguida mapear os valores tradicionais da cultura nordestina, identificar as ameaças a que estes estavam submetidos e propor as estratégias para sua valorização/preservação. Entre os valores culturais enaltecidos, destacamse aspectos da arquitetura habitacional (com ênfase nos mucambos) e da culinária regional. Em segundo plano, aparecem outros costumes regionais como a indumentária e a relação harmônica com a fauna e a flora.

Nossa análise do Manifesto ${ }^{27}$ limita-se exclusivamente à revisão dos conteúdos de oito dessas seções (X a XVII), localizadas entre as páginas 30 a 45, onde Freyre versa sobre a valorização da culinária regional nordestina, temática pertinente ao nosso campo do conhecimento e atuação. Nessa releitura, de forma livre e flexível, tomaremos como guias de interpretação alguns conceitos e concepções. Entre tais conceitos e concepções, explicitamos: área alimentar, segundo Josué de Castro; ${ }^{34}$ sistema alimentar, conforme Hernández \& Arnáiz; $;^{35}$ espaço social alimentar, segundo Poulain e Proença; ${ }^{36}$ culinária, conforme adotado por Diez-Garcia e Castro; ${ }^{11}$ campo científico, habitus e capital simbólico, segundo Bourdieu; ${ }^{37,38}$ paradigma, conforme Kuhn ${ }^{39}$; e sociedade em rede, segundo Castells. ${ }^{40}$ 
As regiões culinárias do Brasil segundo o Manifesto Regionalista

Ao longo do Manifesto, ${ }^{27}$ bem como nas obras de Freyre que analisamos, ${ }^{26,31,32,41}$ não localizamos um conceito expresso e explícito de culinária regional, região culinária e/ou cozinha regional. Por dedução, consideramos que tal conceito deva estar bem próximo daquele usado por Josué de Castro (1908-1973), em seu clássico Geografia da Fome ${ }^{34}$ - área alimentar, o qual é definido como determinada região geográfica que

[...] dispondo de recursos típicos, com sua dieta habitual apoiada em determinados produtos regionais e com seus efetivos humanos refletindo, em muitas de suas características, tanto somáticas como psíquicas, tanto biológicas como culturais, a influência marcante dos seus tipos de dieta (p. 58-59).

É preciso, no entanto, deduzir que a concepção de região culinária, para Freyre, ${ }^{27}$ deve ter sido fundada em paradigmas muito mais histórico-culturais e político-ideológicos do que em paradigmas geográficos. Na mesma direção, é preciso reconhecer também a amplitude da concepção geográfica contida em Josué de Castro. ${ }^{34}$ Para nos guiar e, sobretudo, nos atualizar na compreensão dos conceitos de Culinária Regional e Área Alimentar (tendo em vista o contexto histórico em que os mesmos foram empregados/formulados), remetemos o leitor aos conceitos de sistema alimentar, segundo Hernández \& Arnáiz; ${ }^{35}$ de espaço social alimentar, conforme Poulain e Proença, ${ }^{36}$ e de culinária, conforme adotado por Diez-Garcia e Castro. ${ }^{11}$

À época do Manifesto (1926), ${ }^{27}$ Freyre destacou a existência de três regiões culinárias principais [termo usado por Freyre] do Brasil: 1) Região Culinária Baiana; 2) Região Culinária Nordestina; e 3) Região Culinária Mineira. Entretanto, sem descrever o que caracterizava estas três principais regiões culinárias, ele referia que “outras tradições culinárias 'menos importantes' [destaque nosso] poderiam ser acrescentadas, com suas cores próprias, ao mapa que se organizasse das variações de mesa, sobremesa e tabuleiro em nosso país” (p. 31). Nesse sentido, ele aponta a existência de mais quatro regiões culinárias, a saber: 1) Região Culinária do Extremo Norte; 2) Região Culinária Fluminense e Oeste-Paulista; 3) Região Culinária Gaúcha; e 4) Região Culinária Sertão.

Segundo Freyre, ${ }^{27}$ a região culinária do Extremo Norte, com predominância de influência indígena, caracterizava-se pelos complexos culinários da tartaruga, da castanha e do açaí. A região culinária Fluminense e o Oeste-Paulista caracterizavam-se por idênticas tradições agráriopatriarcais e pelo mesmo uso farto do açúcar que a Região Culinária Nordestina. A Região Culinária Gaúcha foi descrita como tendo uma "mesa um tanto rústica, embora mais farta que as outras em boa carne, caracteristicamente comida como churrasco quase cru e à faca de ponta” (p. 32). Por fim, a região culinária Sertão, que compreendia áreas

[...] caracterizadas por uma cozinha ainda agreste; pelo uso da carne seca, de sol ou do Ceará com farinha de leite, da umbuzada e do requeijão; pelo uso também do quibebe, franciscanamente simples, e da rapadura; e nas florestas do centro do país pela utilização da caça e do peixe de rio - tudo ascética e rusticamente preparado (p. 32). 
A caracterização das regiões culinárias do Brasil realizada por Freyre no Manifesto ${ }^{27}$ apresenta muita semelhança com os conceitos e caracterização das áreas alimentares brasileiras apresentados por Josué de Castro em Geografia da Fome, ${ }^{34}$ objeto de análise em estudo anterior. ${ }^{42}$ Vamos recordar que, em vez de trabalhar com o conceito de região culinária, Castro usou em Geografia da Fome ${ }^{34}$ os conceitos de áreas e subáreas alimentares, regime alimentar, dieta habitual, dieta básica, cultura alimentar, hábitos alimentares, padrão alimentar e mosaico alimentar brasileiro. Ressaltamos que em raríssima passagem de Geografia da Fome ${ }^{34}$ (p. 163), identificamos o uso das expressões cozinha do Nordeste e cozinha baiana, termo (cozinha) usado por Freyre tanto no Manifesto, ${ }^{27}$ como em outras de suas obras, tais como Casa-grande e senzala, ${ }^{26}$ Sobrados e mucambos, ${ }^{41}$ Nordeste ${ }^{32}$ e Açúcar. ${ }^{31}$ Nas obras de Freyre, os termos relacionados mais usados são: alimentação, comida, cozinha, culinária, dieta, hábitos de dieta, receitas, regime alimentar (também usado por Josué de Castro), tradições culinárias e valores culinários.

Vale destacar que, em comparação à caracterização das regiões culinárias do Brasil realizada por Freyre no Manifesto, ${ }^{27}$ o mapa das cinco áreas alimentares brasileiras traçado por Josué de Castro em Geografia da Fome ${ }^{34}$ é muito mais completo, amplo e detalhado. Ressalta-se, entretanto, a antecedência da abordagem de Freyre, uma vez que o Manifesto foi divulgado originalmente em 1926; ${ }^{27,33}$ Casa-grande e senzala, em 1933; ${ }^{26}$ Sobrados e mucambos, em 1936; ${ }^{41}$ Nordeste, em $19377^{32}$ e Açúcar, em 1939, ${ }^{31}$ enquanto a primeira edição de Geografia da Fome foi realizada em 1946. ${ }^{34,35}$

Parece-nos que essa linha de análise usada por Freyre no Manifesto, ${ }^{27}$ tomando a culinária regional como um dos pilares centrais de explicação/constituição do processo identitário de uma população, foi bastante original e ousada para o contexto de sua divulgação. De fato, conforme apontado em estudo anterior, ${ }^{25}$ a abordagem sociológica que Freyre introduziu no início da década de 1930, sobre o padrão e os hábitos alimentares da sociedade brasileira, enfocando particularmente seus aspectos socioculturais, teve forte influência sobre os cientistas brasileiros que participavam do processo de constituição do campo da Nutrição. Nesse sentido, Casa-grande e senzala, ${ }^{26}$ publicado originalmente em 1933, foi considerado como o primeiro e mais completo ensaio sociológico sobre o padrão e os hábitos alimentares da sociedade brasileira. ${ }^{25}$

Na sequência, dando continuidade à matriz analítica iniciada no Manifesto, ${ }^{27}$ podemos considerar Sobrados e mucambos, ${ }^{41}$ publicado originalmente em 1936, como o segundo e mais completo ensaio socioantropológico sobre o padrão e os hábitos alimentares da sociedade brasileira. Em Nordeste, ${ }^{32}$ publicado originalmente em 1937, de forma menos densa que em Casa-grande e senzala ${ }^{26}$ e Sobrados e mucambos, ${ }^{41}$ também identificamos importante contribuição original sobre aspectos positivos e negativos da influência da monocultura da cana de açúcar sobre o padrão e os hábitos alimentares da sociedade brasileira. Em Açúcar, ${ }^{31}$ publicado originalmente em 1939, também de forma original e ousada, Freyre faz uma importante compilação de receitas tradicionais de bolos e doces do Nordeste brasileiro, fechando, ao que nos parece, o ciclo de análise iniciada no Manifesto, ${ }^{27}$ a qual toma a culinária como um dos pilares da autenticidade da formação social brasileira. 
Ressalta-se, ainda, que o mapa das cinco diferentes áreas alimentares brasileiras traçado por Josué de Castro ${ }^{34}$ parece caracterizar-se pela centralidade de "aspectos geográficos", enquanto a abordagem das sete regiões culinárias descritas por Freyre no Manifest $0^{27}$ parece dar destaque aos "aspectos culturais". Ambas as abordagens apresentam elementos de comunhão, bem como de discordância.

Assim, as cinco diferentes áreas alimentares definidas por Josué de Castro em Geografia da Fome ${ }^{34}$ foram distribuídas da seguinte forma: (1) Área Alimentar Amazônica - à época, abrangia os estados do Amazonas e Pará, parte dos estados do Mato Grosso, Goiás e Maranhão e os territórios do Amapá e Rio Branco. Pelas características relatadas, correspondia à Região Culinária do Extremo Norte identificada por Freyre no Manifesto, ${ }^{27}$ (2) Área Alimentar Nordeste Açucareiro ou Zona da Mata Nordestina - à época, correspondia a todo o litoral nordestino, do Estado da Bahia ao Ceará, compreendendo uma faixa territorial com largura média de $80 \mathrm{~km}$. Pelas características relatadas correspondia à Região Culinária Nordestina identificada por Freyre no Manifesto, ${ }^{27}$ (3) Área Alimentar Sertão Nordestino - correspondendo, à época, às terras centrais dos estados do Piauí, Ceará, Rio Grande do Norte, Paraíba, Pernambuco, Alagoas, Sergipe e Bahia. Pelas características relatadas correspondia, em parte, à Região Culinária Sertão identificada por Freyre no Manifesto, ${ }^{27}$ (4) Área Alimentar Centro-Oeste - compreendia os estados de Minas Gerais, Goiás e Mato Grasso. Pelas características relatadas, poderia corresponder à Região Culinária Mineira e, em parte, à Região Sertão, identificadas por Freyre no Manifesto, ${ }^{27}$ e (5) Área Alimentar Extremo Sul - que à época abrangia os estados da Guanabara, Rio de Janeiro, São Paulo, Paraná, Santa Catarina e Rio Grande do Sul. Pelas características relatadas, correspondia às Regiões Culinárias Fluminense, Oeste-Paulista e Gaúcha identificadas por Freyre no Manifesto. ${ }^{27}$

É preciso ressaltar, ainda, que em relação à Região Alimentar Extremo Sul, Josué de Castro destacou a presença de distintas subáreas alimentares na região: (1) Subárea de influência italiana, caracterizada pelo largo consumo de trigo sob a forma de macarrão, ravioli e spaghetti; (2) Subárea localizada no Rio Grande do Sul, caracterizada pelo complexo alimentar do churrasco e do mate-chimarrão; (3) Subárea de influência japonesa, localizada em torno da capital de São Paulo e outros centros urbanos, caracterizada por abundante consumo de verduras; e (4) Subárea de influência germânica, caracterizada por um consumo mais frequente de aveia, centeio, lentilhas, hortaliças, frutas, carne de porco (salsichas, bacon, presunto, defumados), pão preto, chucrute e cerveja. $^{34,42}$ Portanto, a única dessas subáreas alimentares de Geografia da Fome ${ }^{34}$ que teria uma região culinária correspondente de acordo com a descrição do Manifesto ${ }^{27}$ seria a do Rio Grande do Sul (Região culinária gaúcha). Entretanto, em outras passagens do Manifesto ${ }^{27}$ e em outras obras de Freyre, descritas anteriormente, tais como Sobrados e mucambos ${ }^{41}$ e Nordeste, ${ }^{32}$ é possível observar passagens em que o autor faz alusão às influências de outros grupos étnico-culturais (alemãs, árabes, espanhóis, holandeses, israelitas, italianos, sírios) na constituição da culinária brasileira.

Por sua vez, em relação à Região Alimentar Nordeste Açucareiro, Josué de Castro apontou a existência de distintas subáreas alimentares nessa região nordestina. Inicialmente, fez distinção 
entre duas subáreas alimentares: a litorânea e a da mata ou da cana-de-açúcar. Ao longo da sua abordagem fez referência a uma subárea alimentar do sururu no Estado de Alagoas e à especificidade da cozinha baiana. Ao final, também descreveu a área alimentar do cacau que, à época, se estendia do Recôncavo para o sul da Bahia até o Espírito Santo. ${ }^{34,42}$ Portanto, os pontos concordantes entre o Manifesto ${ }^{27}$ e a Geografia da Fome $e^{34}$ são as caracterizações culinárias do Nordeste Açucareiro e da cozinha baiana.

\section{As influências étnico-culturais na constituição da Culinária Brasileira}

Em estudo anterior, ${ }^{25}$ que teve como foco a análise sobre o padrão de consumo e os hábitos alimentares da sociedade colonial brasileira realizada por Freyre em Casa-grande e senzala, ${ }^{26}$ identificou-se que a abordagem desse autor tinha como pressupostos a articulação simultânea de três enfoques explicativos: étnico-cultural, econômico-social e geográfico.

No enfoque étnico-cultural, Freyre procurava demonstrar que foi a mistura das cozinhas (culinárias) das três raças (índio brasileiro, negro africano e branco português) que constituiu a cozinha mestiça, para ele a autêntica cozinha brasileira. No enfoque econômico-social, ele concebia que a cozinha brasileira, particularmente da zona da mata açucareira, foi produto do sistema econômico-social baseado na monocultura latifundiária escravocrata. E no enfoque geográfico, ele considerava que determinadas condições físico-geográficas, tais como solo, clima e pluviosidade, contribuíram para a formação da cozinha nacional..$^{25}$

No Manifesto, ${ }^{27}$ entretanto, talvez pelas características da obra, a abordagem de Freyre sobre a valorização da culinária regional teve como foco central as influências étnico-culturais. Nesse sentido, ele defendia a tese de que a base e a estética das principais cozinhas regionais brasileiras são produtos de três grandes influências étnico-culturais: a portuguesa, a africana e a ameríndia. No entanto, ao longo de sua argumentação, conforme citamos anteriormente, ele também aponta a existência de outras influências étnico-culturais que contribuíram para a diversificação e as especificidades das culinárias regionais.

O mapa de distribuição geográfica dessas influências étnico-culturais foi assim traçado por Freyre: ${ }^{27}$ 1) No litoral, do Maranhão ao Rio de Janeiro ou a Santos, prevalecia a influência portuguesa; 2) Na Bahia, sobressaía a influência africana; 3) No extremo Norte, a influência ameríndia era particularmente notável; 4) No Rio Grande do Sul e em Santa Catarina, encontravamse "traços consideráveis de influência espanhola e de influência alemã, a darem novos sabores aos pratos e novas aparências aos velhos hábitos lusitanos, açorianos ou paulistas de alimentação" (p. 32); 5) Em São Paulo e no Paraná, ele identificava a existência de "sinais de influência italiana e alguma influência síria ou árabe, além da israelita, presente também no Rio de Janeiro” (p. 32); 6) No Nordeste agrário, segundo ele, parecia ocorrer um melhor equilíbrio ou harmonização das 
três influências predominantes: não haveria "nem excesso português como na capital do Brasil [à época, Rio de Janeiro], nem excesso africano como na Bahia, nem quase exclusividade ameríndia como no extremo Norte" (p. 33). Portanto, para Freyre, ${ }^{27}$ era a culinária nordestina a que melhor expressava a síntese ou o sincretismo das cozinhas das três raças (ameríndia, portuguesa e africana), sendo a que melhor representaria/expressaria a cozinha brasileira.

Críticas sobre esta concepção de Freyre são frequentes na literatura analisada. ${ }^{21-24,28-30}$ Amaral Jr., ${ }^{28}$ por exemplo, ao criticar a tese de que o tipo étnico-cultural nordestino seria representativo da identidade nacional, argumentou que a mesma deveria ser analisada no contexto histórico que a gerou - momento de choque entre sociabilidades tradicionais e modernas, advindo do declínio da sociedade agrário-patriarcal escravocrata e a ascensão da sociedade capitalista urbano-industrial. Cabe relembrar que a história de vida de Freyre estava intimamente identificada com a sociedade agrário-patriarcal escravocrata pernambucana. ${ }^{25}$ Para Amaral Jr., ${ }^{28}$ a abordagem de Freyre sobre a região Nordeste constituiu um dos principais elementos na construção histórica do conceito de identidade nordestina (nordestinidade) e mesmo de Nordeste como emblema identitário e ideológico. Essa abordagem de Freyre, segundo Amaral Jr., ${ }^{28}$ se explicava por dois motivos românticos: "o sonho da comunidade ideal e a hostilidade para com a racionalidade burguesa ocidental" (p. 229).

A dualidade entre tradicional e moderno, rural e urbano, passado e futuro, preservação e transformação, regional e universal e outras ambivalências, irá caracterizar a abordagem de Freyre sobre hibridismo ou interpenetração de culturas contida tanto no Manifesto ${ }^{27}$ como no conjunto de suas obras, conforme apontam muitos dos seus intérpretes..$^{28-30,33}$

Nas seções que se seguem, essa discussão sobre a abordagem das influências étnico-culturais que contribuíram para a formação da cozinha regional/nacional contida no Manifesto ${ }^{27}$ será retomada, uma vez que examinaremos as contribuições específicas apontadas por Freyre para cada elemento étnico-cultural.

\section{A contribuição da culinária portuguesa}

$\mathrm{Na}$ abordagem freyreana contida no Manifesto, ${ }^{27}$ sobre as influências étnico-culturais da cozinha brasileira em geral, e do Nordeste agrário em particular, o papel do branco colonizador (português) ganhou evidente centralidade. Para Freyre, sem a contribuição do colonizador português, "bem diversa seria a situação culinária do Brasil. Não haveria unidade nacional sob a variedade regional" (p. 33).

Ressalta-se a interessante análise que Freyre ${ }^{27}$ realiza sobre o processo de constituição da própria culinária portuguesa, evidenciando que os valores culinários trazidos pelos portugueses para o Brasil foram produtos históricos assimilados de distintas culturas culinárias: 
O português com seu gênio de assimilação trouxera para sua mesa alimentos, temperos, doces, aromas, cores, adornos de pratos, costumes e ritos de alimentação das mais requintadas civilizações do Oriente e do Norte da África. Esses valores e esses ritos se juntaram a combinações já antigas de pratos cristãos com quitutes mouros e israelitas, entre os quais, segundo parece, se deve situar o famoso cozido à portuguesa, parente do "puchero". O costume da feijoada "dormida" parece ter sido assimilado pelo luso-brasileiro, do israelita, amigo desses mistérios por gasto e pela necessidade de esconder certos quitutes como que de ritual ou liturgia, dos olhos de cristãos velhos (p. 33-34).

De fato, conforme aponta Freyre, ${ }^{27}$ o colonizador português já trouxe para o Brasil uma culinária lusitana mesclada pela interpenetração de distintos valores culinários, oriundos das inter-relações econômico-comerciais e sociais contraídas entre Portugal, suas colônias e parceiros comerciais, dentro do contexto do mercantilismo e das grandes navegações.

A análise de Freyre $^{27}$ também permite identificar evidências de como as tradições culinárias trazidas pelos portugueses foram "reinventadas" no Brasil, em funções de distintas condições ambientais, econômicas e histórico-sociais:

Todas essas tradições de mesa e sobremesa de Portugal - a cristã, a pagã, a moura, a israelita, a palaciana, a burguesa, a camponesa, a monástica ou fradesca, a freirática - transmitiu-as de algum modo Portugal ao Brasil, onde as matronas portuguesas [...] não tardaram a aventurar-se a combinações novas com as carnes, os frutos, as ervas e os temperos da terra americana. Aventuras de experimentação continuadas pelas brasileiras senhoras de engenho, pelas sinhás das casas-grandes, umas, grandes quituteiras, outras, doceiras, quase todas peritas no fabrico do vinho de caju, do licor de maracujá, da garapa de tamarindo: símbolos da hospitalidade patriarcal nesta parte do Brasil, antes do "cafezinho" ter-se generalizado como sinal de cortesia ou boas vindas. Por outro lado, onde se foi levantando um mosteiro ou um recolhimento de religiosos ou um convento de freiras é quase certo que foi também se erguendo no Brasil um novo reduto de valores culinários. Um novo laboratório em que frades ou freiras se especializaram em inventar novas combinações culinárias, dentro das boas tradições portuguesas [...]. (p. 34-35).

Importante destacar a descrição feita por Freyre sobre o papel da mulher (matronas portuguesas, senhoras de engenho, sinhás das casas-grandes), em primeiro plano e, em segundo plano, dos religiosos (frades ou freiras) no processo de transmissão e invenção de tradições/valores culinários. No interior da sociedade patriarcal, centrada na hegemonia do gênero masculino, a cozinha/culinária revelou-se importante locus para realização do poder feminino. Tal passagem nos leva a interpretá-la à luz dos conceitos de campo, habitus e capital simbólico, contidos em Bourdieu. ${ }^{37,38}$

Outro destaque diz respeito à referência sobre a incorporação do hábito alimentar de oferecer/ tomar "cafezinho" em oposição ao vinho de caju, ao licor de maracujá e à garapa de tamarindo - símbolos da hospitalidade patriarcal para Freyre. É um interessante exemplo culinário da ambivalência freyreana em retratar a oposição entre valores culinários tradicionais e valores culinários modernos, entre Culinária Regional e Culinária Global. Neste caso, percebe-se certa 
rejeição/negação do autor do Manifesto ${ }^{27}$ a incorporar um novo hábito alimentar oriundo da ascensão da economia cafeeira, em oposição ao desejo de preservação de hábitos alimentares vinculados à decadente economia canavieira.

\section{A contribuição da culinária indígena}

Embora no Manifesto ${ }^{27}$ Freyre faça referência à influência ameríndia e africana na constituição da cozinha brasileira, os registros sobre a contribuição específica da cozinha ameríndia são muito escassos ou quase inexistentes. Em uma das poucas passagens em que a participação dessa culinária é referida, ele relata que "a tais mestres [os portugueses e seus descendentes] se juntaram cunhãs e negras Minas com seu saber também considerável de ervas, de temperos, de raízes, de frutos, de animais dos trópicos" (p. 35).

Ressaltamos, portanto, essa importante limitação do Manifesto ${ }^{27}$ em relação a não ter explorado com a devida profundidade a contribuição da culinária ameríndia na conformação da cozinha nacional. Essa lacuna também pode ser extrapolada para outras obras de Freyre, tais como Casa-grande e senzala ${ }^{26}$ Outros autores, como Santos, ${ }^{43}$ também já identificaram essa subestimação da abordagem freyreana sobre a contribuição da cultura indígena na conformação da culinária brasileira. Para Santos, ${ }^{43}$ a abordagem hierárquica que Freyre realiza sobre as três principais culturas que influenciaram a constituição da culinária brasileira, colocando a cultura indígena num patamar inferior, abaixo das culturas africana e portuguesa, talvez se explique pelo fato de o indígena não estar no foco das relações socioeconômicas da sociedade agrário-patriarcal, nem tão íntimo do cotidiano das famílias dos senhores de engenho (das casas-grandes), como estavam os negros africanos - foco central da análise do autor de Casa-grande e senzala. ${ }^{26}$

Analisando obras de Gilberto Freyre e de Câmara Cascudo (1898-1986), ${ }^{44}$ Tempass ${ }^{45}$ também procura elencar possíveis razões para a negligência de tais autores e, consequentemente, para a invisibilidade da doçaria de origem indígena no processo de formação da culinária nacional. Para Tempass, ${ }^{45}$ muito além de simples fornecedores de ingredientes nativos, os indígenas brasileiros contribuíram com um complexo savoir-faire para a culinária brasileira. Diante das condições ambientais e histórico-sociais dos primeiros séculos de colonização do Brasil, a utilização e/ou adaptação do sistema alimentar (tendo por base o conceito proposto por Hernández \& Arnáiz ${ }^{35}$ ) dos indígenas brasileiros foram estratégias vitais que possibilitaram a fixação dos portugueses e outros povos europeus no país.

No caso específico da doçaria nacional, Tempass ${ }^{45}$ advoga que coube às portuguesas e africanas o papel de substituir, nas preparações nativas, o mel de abelha usado pelos indígenas pelo açúcar ou melado de cana de açúcar usado pelos colonizadores. Advoga ainda que as portuguesas também adaptaram os inúmeros ingredientes nativos para as receitas já tradicionais de doces trazidas de Portugal. 
Em relação às razões para a invisibilidade da cultura indígena, ele aponta fatores vinculados à origem e distinção de classe social, de gênero e representação social dos primeiros colonizadores, cronistas e autores clássicos, os quais influenciaram o sub-registro histórico da contribuição da culinária indígena na formação da cozinha nacional. ${ }^{45}$

\section{A contribuição da culinária africana}

A contribuição da culinária africana, por sua vez, é registrada em diversas passagens do Manifesto ${ }^{27}$. Em uma dessas passagens, Freyre relata:

Enquanto isto foi se mantendo a tradição, vinda de Portugal, de muito quitute mourisco ou africano: o alfenin, o alfeolo, o cuscuz, por exemplo. Foram eles se conservando nos tabuleiros ao lado dos brasileirismos: as cocadas - talvez adaptação do doce indiano, as castanhas de caju confeitadas, as rapaduras, os doces secos de caju, o bolo de goma, o munguzá, a pamonha servida em palha de milho, a tapioca seca e molhada, vendida em folha de bananeira, a farinha de castanha em cartucho, o manue (p. 36).

As "baianas" (seus quitutes e seus tabuleiros) são exaltadas em várias passagens do Manifesto, ${ }^{27}$ denotando a importância de sua contribuição para a conformação da cozinha brasileira na abordagem freyreana:

E o tabuleiro foi se tornando, nas principais cidades do Brasil, e não apenas do Nordeste, uma arte, uma ciência, uma especialidade das "baianas" ou das negras: mulheres, quase sempre imensas de gordas que, sentadas a esquina de uma rua ou a sombra de uma igreja, pareciam tornar-se, de tão corpulentas, o centro da rua ou do pátio da igreja. Sua majestade era às vezes a de monumentos. Estátuas gigantescas de carne. E não simples mulheres iguais às outras (p. 36).

Nessa passagem, o que nos chama a atenção é uma das características do perfil nutricional das "baianas" traçado por Freyre - mulheres quase sempre imensas de gordas, o que pode estar associado à emergência da obesidade a partir do sistema agrário-patriarcal escravocrata. De fato, em outras obras de Freyre, identificamos em várias passagens registros que nos remetem à existência de um ambiente alimentar e nutricional obesogênico, compartilhado por todos os segmentos sociais. Em muitas dessas passagens, tais características do perfil nutricional da população, relacionadas à obesidade, são relatadas por Freyre como associadas aos hábitos alimentares baseados no consumo da cana de açúcar e seus derivados. Temática interessante que precisaria ser explorada em futuras investigações.

No nosso entendimento, entretanto, no Manifesto, ${ }^{27}$ talvez pelas características da obra, embora enfatizado, o papel da influência africana na constituição da cozinha nordestina, em particular, e da cozinha brasileira, em geral, também foi subestimado ou muito pouco explorado. Em outras obras de Freyre, como Casa-grande e senzala ${ }^{26}$ e Sobrados e mucambos, ${ }^{41}$ o registro de tal influência é feito com muito rigor e preciosidade. 
Em estudo anterior, ao analisar Casa-grande e senzala, ${ }^{26}$ Vasconcelos ${ }^{25}$ observou que nessa obra Freyre procurou registrar uma série de evidências com o intuito de demonstrar que foi a mistura das cozinhas das três raças que constituiu a cozinha mestiça - para ele, a autêntica cozinha brasileira. Entretanto, para Vasconcelos, ${ }^{25}$ ao longo da análise daquela obra, ${ }^{26}$ parece que Freyre procura atribuir maior peso à contribuição do escravo africano. Umas das passagens destacadas por Vasconcelos ${ }^{25}$ evidencia a concepção do hibridismo das três raças:

Para as necessidades de alimentação foram-se cultivando de norte a sul, através dos primeiros séculos coloniais, quase as mesmas plantas indígenas ou importadas. Na farinha de mandioca fixou-se a base do nosso sistema de alimentação. Além da farinha cultivou-se o milho; e por toda parte tornou-se quase a mesma a mesa colonial, com especializações regionais apenas de frutas e verduras: dando-lhe mais cor ou sabor local em certos pontos a maior influência indígena; noutros, um vivo colorido exótico a maior proximidade da África; e em Pernambuco, por ser o ponto mais perto da Europa, conservando-se um equilíbrio entre as três influências: a indígena, a africana e a portuguesa (p. 32).

\section{Contribuições dos engenhos patriarcais para uma culinária regional}

Ao descrever as possíveis contribuições dos engenhos de cana de açúcar (engenhos patriarcais) para a culinária da região Nordeste, Freyre $^{27}$ realiza, de fato, um precioso relato dos hábitos alimentares dos senhores de engenhos ou proprietários das casas-grandes. Entretanto, em relação à descrição muito mais detalhada sobre os hábitos alimentares da sociedade patriarcal contida em Casa-grande e senzala ${ }^{26}$ e em Sobrados e mucambos, ${ }^{41}$ observa-se que o relato sobre esta temática contido no Manifesto, ${ }^{27}$ embora relevante e interessante, foi muito subestimado. Quanto aos valores culinários dos senhores de engenhos, o relato do Manifesto ${ }^{27}$ exalta a diversidade e a fartura das mesas, principalmente em dias de festividade:

Dos velhos engenhos da região é raro o que não tenha tido sua especialidade culinária mesmo modesta: um quibebe ou um pirão ou uma farofa mais gostosa que as outras. [...] E de vários engenhos mais ricos se sabe que, para regalo dos papa-pirões, conservaram até há pouco tempo a tradição da mesa larga e sempre pronta a receber hóspedes, como se todo dia fosse neles dia santo ou dia de festa: sábado de aleluia, alegrado pelas fritadas de siris; São João colorido pelo amarelo das canjicas salpicadas de canela e pelas pamonhas envolvidas em palha de milho verde; ou Carnaval adoçado pelos filhós com mel de engenho. Tradição, essa de casa de engenho de mesa farta, vindo de época remota (p. 37-38).

Em relação à fartura das mesas das classes dominantes, em determinada passagem do Manifesto ${ }^{27}$ aparece uma breve e irônica menção à possível contribuição da culinária holandesa aos hábitos alimentares regionais. De fato, verifica-se uma nítida subestimação realizada por Freyre ${ }^{27}$ quanto à influência holandesa na constituição da culinária regional: 
As crônicas do dominio holandês no Nordeste registram igualmente jantares e até banquetes suntuosos, alguns dados pelo próprio Conde Maurício de Nassau, a homens importantes da terra, naturalmente para amaciar neles o ódio à invasão nórdica que, aliás, deixou na língua do Nordeste um nome holandês de comida: brote (p. 38).

Em outra passagem do Manifesto, ${ }^{27}$ Freyre relata os requintes culinários dos sobrados e casas nobres da cidade de Recife, verificados a partir de fins do século XVIII, com a decadência do sistema agrário-patriarcal:

Eram casas onde se comia principescamente bem, as dos príncipes recifenses do comércio, da magistratura, da política, das letras, das armas. Onde desde a meninice ioiós e iaiás dengosas tomavam chá da Índia com sequilhos [...]. E tudo isso, em porcelana da melhor, da mais fina, da mais bela. Comido com talher de prata, mexido com colher da melhor prata portuguesa (p. 38-39).

Entretanto, na leitura do Manifesto ${ }^{27}$ verifica-se total omissão sobre o consumo e os hábitos alimentares dos moradores das senzalas e das populações pobres moradoras nos engenhos e suas proximidades. Em outras obras de Freyre, comentadas anteriormente, sobretudo Sobrados e mucambos $^{41}$ e Nordeste, ${ }^{32}$ entretanto, observa-se preciosa e detalhada caracterização do consumo e dos hábitos alimentares desses segmentos sociais.

Em Sobrados e mucambos ${ }^{41}$ (p. 196), em uma das inúmeras passagens sobre o consumo e os hábitos alimentares das populações pobres, Freyre descreve:

Ao contrário dos escravos domésticos dos sobrados que participavam, como nas casas-grandes dos engenhos, da alimentação patriarcal, a pobreza livre desde os tempos coloniais teve de ir se contentando, nos mucambos, nas palhoças, nos cortiços, nas próprias casas térreas, nos próprios sobrados ou sobradinhos de aluguel, com o bacalhau, a carne seca, a farinha e as batatas menos deterioradas que comprava nas vendas e nas quitandas. E com uma insignificância de carne fresca e de vaca.

Em outra passagem de Sobrados e mucambos ${ }^{41}$ (p. 202), Freyre também descreve sobre o consumo de outro alimento de origem animal - o peixe - pelas camadas populares:

Quase o mesmo sucedia com relação ao peixe, que à primeira vista se supõe fosse um alimento fácil para a gente mais pobre das cidades; para a população das casas térreas, dos mucambos e dos cortiços dos fins do século XVIII e dos primeiros decênios do XIX. Mas também o suprimento de peixe tornou-se um comércio dominado por grandes proprietários de terras, donos, no Nordeste, de currais entre as praias e os arrecifes ou com viveiro dentro do sítio; pelos atravessadores e pela própria burguesia dos sobrados.

Em Nordeste ${ }^{32}$ (p. 109), por exemplo, ao analisar os efeitos negativos da monocultura da cana de açúcar sobre as condições de vida e alimentação da população trabalhadora, ele comenta:

Daí desequilíbrios profundos na vida e na alimentação da gente do "litoral" e da "mata", sobretudo da gente das casas de barro, a gente pobre e aparentemente livre, moradora nos engenhos de cana; mas impedida, como 
se fosse escrava, de criar bicho, de plantar legume, de cultivar a terra de outro jeito que não fosse a serviço - e serviço imediato - da monocultura da cana e dos seus senhores. Daí a falta de carne, de leite, de queijo, de legume, de fruta na mesa de grande parte da gente do Nordeste açucareiro [...], contrariando a suposição de que os velhos engenhos patriarcais fossem todos pedaços idílicos de algum extraordinário país de Cocagne.

\section{Ameaças aos valores culinários do Nordeste segundo o Manifesto}

As mudanças que passariam a ocorrer, a partir dos anos 1920-1930, nos hábitos alimentares e culinários da população brasileira, particularmente da Região Nordeste, que foram prenunciadas por Freyre em diversas passagens do Manifesto. ${ }^{27}$ A chegada da sociedade urbano-industrial trazia consigo ameaças às tradições culinárias da Região Nordeste e sobretudo da região habitada por Freyre - a capital do estado de Pernambuco (Recife). Nesta perspectiva, já nos primeiros anos da década de 1920, ele prenunciava que "todos os pratos tradicionais e regionais do Nordeste estão sob a ameaça de desaparecer, vencidos pelos estrangeiros e pelos do Rio" ${ }^{27}$ (p. 39).

O relato de Freyre ${ }^{27}$ sobre os produtos servidos (vendidos) nas cafeterias do Recife dos primeiros anos 1920 é um precioso registro das mudanças nos hábitos alimentares que já começam a ocorrer. A substituição do consumo de alimentos e bebidas tradicionais/regionais por alimentos industrializados, por receitas e preparações estrangeiras, foi assim identificada:

Ao voltar da Europa há três anos, um dos meus primeiros desapontamentos foi o de saber que a água de coco verde era refresco que não se servia nos cafés elegantes do Recife, onde ninguém deve lembrar-se de pedir uma tigela de arroz doce ou um prato de munguzá ou uma tapioca molhada. [...] Os cafés elegantes do Recife não servem senão doces e pastéis afrancesados e bebidas engarrafadas (p.40).

Nessa passagem, observa-se outro interessante exemplo culinário da ambivalência freyreana em identificar as ameaças aos valores culinários tradicionais da cozinha nordestina, a partir de evidente oposição entre água de coco verde (planta introduzida no país pelos colonizadores portugueses) ${ }^{44}$ e bebidas engarrafadas (possivelmente a introdução dos refrigerantes aos hábitos alimentares brasileiros), entre arroz doce, munguzá e tapioca (preparações culinárias tradicionais que sintetizam o hibridismo das três raças) ${ }^{26,34,44}$ e doces e pastéis afrancesados (a chamada europeização da culinária regional nordestina). ${ }^{27,41}$ Neste exemplo também se observa a sensibilidade da abordagem cultural freyreana em alertar precocemente sobre os riscos da incorporação de alimentos não saudáveis à culinária regional. Nesse sentido, identificamos a relativa atualidade e sincronia do Manifesto ${ }^{27}$ frente ao movimento contemporâneo que procura incentivar o ato de cozinhar ou o desenvolvimento de habilidades culinárias como estratégia para promover a alimentação adequada e saudável. . $^{818,19-20}$

De forma semelhante, ele também identificou as mudanças que começavam a ocorrer nos hábitos alimentares das classes dominantes do Recife dos anos 1920: 
Nem ao menos por ocasião da Quaresma, voltam essas casas aos seus antigos dias de esplendor. Já quase não há casa, neste decadente Nordeste de usineiros e de novos-ricos, onde aos dias de jejum se sucedam, como antigamente, vastas cheias de peixe de coco, de fritada de guaiamu, de pitu ou de camarão, de cascos de caranguejo e empadas de siri preparadas com pimenta ${ }^{27}(p .40)$.

Àquela época, Freyre ${ }^{27}$ já identificava a crescente substituição de preparações tradicionais feitas em casa por preparações e alimentos industrializados:

Nunca em repudiar tradições tão preciosas para substituí-las por comidas incaracterísticas de conserva e de lata, como as que já imperam nas casas das cidades e começam a dominar nas do interior. Raras são hoje, as casas do Nordeste onde ainda se encontrem mesa e sobremesa ortodoxamente regionais: forno e fogão onde se cozinhem os quitutes tradicionais à boa moda antiga. O doce de lata domina. A conserva impera. O pastel afrancesado reina (p. 41).

Em Sobrados e mucambos, ${ }^{41}$ publicado pela primeira vez em 1936, em inúmeras passagens, Freyre retoma sua abordagem sobre a "europeização" da Culinária Regional, descrevendo de forma detalhada e preciosa as transformações que passariam a ocorrer no consumo e hábitos alimentares da sociedade brasileira, sobretudo a partir da chegada da família real ao Brasil. Vejamos um desses recortes:

Com a maior europeização e a mais larga urbanização dos estilos de vida, o Brasil atravessou um período de muito artigo falsificado e velho a fazer às vezes do bom, do novo, do vindo direto de Paris para as lojas do Rio de Janeiro, do Recife, de Salvador, de São Paulo, de São Luís do Maranhão, de Porto Alegre. [...] As cozinhas das casas grandes e dos sobrados eram decerto umas imundices; mas a comida preparada nelas mais sã que a maior parte da vinda em conserva da Europa. Que a servida às vezes nos hotéis franceses ou pelos cozinheiros italianos. Foi, entretanto, tornando-se chic comer à francesa, à italiana, à inglesa. O chá e a cerveja dos ingleses se propagaram rapidamente entre a fidalguia dos sobrados. Também as massas e os pastéis italianos. O queijo flamengo ou suíço. A própria doçaria das casas grandes, das iaiás solteironas dos sobrados, das freiras dos conventos, dos negros de tabuleiro, foi desaparecendo, perdendo o encanto até para os meninos. E os doces e os doceiros elegantes tornando-se os franceses e italianos, como indicam os anúncios de jornais (p. 366-368, grifo no original).

Na sequência da identificação das ameaças aos valores culinários da região Nordeste, Freyre ${ }^{27}$ deixa evidente sua abordagem conservadora sobre o papel tradicional da mulher no processo de manutenção/conservação da tradição culinária regional - o ato de cozinhar como um atributo feminino:

As novas gerações de moças já não sabem, entre nós, a não ser entre a gente mais modesta, fazer um doce ou guisado tradicional e regional. Já não têm gosto nem tempo para ler os velhos livros de receita de família (p.42). 
Na perspectiva conservadora do papel da mulher na sociedade brasileira e, em particular, na Região Nordeste, ele exalta uma mescla de deveres do universo feminino (maternidade, arte culinária e religiosidade):

Depois dos livros de missa, são os livros de receita de doces e de guisados os que devem receber das mulheres leitura mais atenta. O senso de devoção e o de obrigação devem completar-se nas mulheres do Brasil, tornandoas boas cristãs e ao mesmo tempo boas quituteiras para assim criarem melhor os filhos e concorrerem para a felicidade nacional. Não há povo feliz quando às suas mulheres falta a arte culinária. É uma falta quase tão grave como a da fé religiosa ${ }^{27}(p .42)$.

Na perspectiva freyreana contida no Manifesto, ${ }^{27}$ a arte culinária regional (assim como a arquitetura e a literatura regionais) seria dotada de um papel central no processo civilizatório regional. Nas palavras de Freyre, ${ }^{27}$ a culinária regional "é também uma expressão de civilização, de caráter ou de gênio regional" (p. 43).

Para o autor do Manifesto, ${ }^{27}$ assim como a economia agrário-patriarcal, outros valores como a tradição culinária estavam em declínio ou, pelo menos, em crise, na Região Nordeste. Sendo assim, partindo do pressuposto da centralidade da culinária regional no processo civilizatório de uma população, a perspectiva vislumbrada por Freyre ${ }^{27}$ foi bastante pessimista: "Uma cozinha em crise significa uma civilização inteira em perigo: o perigo de descaracterizar-se” (p. 42).

Nesse sentido, o Primeiro Congresso Regionalista do Nordeste, organizado por Freyre e seus pares, seria um relevante locus para discussão de alternativas contra a descaracterização da culinária regional. Assim, algumas recomendações foram propostas por Freyre ${ }^{27}$ no sentido de evitar as ameaças de descaracterização da culinária regional. Por um lado, tais recomendações a serem adotadas denotam, em seu conjunto, um caráter tão conservador quanto foi sua forma de abordar/identificar tais ameaças:

1-. Que alguém tome a iniciativa de estabelecer no Recife um café ou restaurante a que não falte cor local umas palmeiras, umas piolas de papagaios, um caritó de guaiamu à porta e uma preta de fogareiro, fazendo grude ou tapioca - café ou restaurante especializado nas boas tradições da cozinha nordestina; $2^{\circ}$ - Que os colégios de meninas estabeleçam cursos de cozinh a em que sejam cultivadas as mesmas tradições; $3^{\circ}$ - Que todos quantos possuirem em casa cadernos ou manuscritos antigos de receitas de doces, bolos, guisados, assados, etc., cooperem para a reunião dessa riqueza, hoje dispersa em manuscritos de família ${ }^{27}(p .43)$.

Por outro, as recomendações do Manifesto $0^{27}$ também expressam a ambivalência característica da abordagem freyreana:

O ideal seria que o Recife tivesse o seu restaurante regional, onde se cultivassem a doçaria e a culinária antigas, no meio de um resto de mata também antiga e regional como a de Dois Irmãos, onde a pessoa da terra ou de fora se regalasse comendo tranquilamente sua paca assada ou sua fritada de guaiamu com pirão e molho de pimenta à sombra de paus d'arco, de visgueiros, de mangueiras; onde as crianças se deliciassem com castanha confeitada, garapa de tamarindo, bolo de goma [...] (p. 44). 
Destaca-se que das recomendações formuladas no Manifesto, ${ }^{27}$ pelo menos a de número 3 Freyre conseguiu concretizar, em parte, com a publicação, em 1939, de Açúcar - Uma sociologia do doce, com receitas de bolos e doces do Nordeste do Brasil. ${ }^{31}$

\section{Consideraçóes finais}

Essa releitura do Manifesto Regionalista de $1926^{27}$ denota o pioneirismo de Freyre em chamar a atenção para as ameaças de descaracterização que a culinária regional nordestina, sobretudo pernambucana, passava a sofrer a partir do declínio da sociedade agrário-patriarcal escravocrata e da ascensão da economia capitalista urbano-industrial. Chama a atenção também o pioneirismo das estratégias recomendadas para a valorização/preservação da estética e tradição da cozinha nordestina, por ele considerada aquela que melhor expressava a síntese ou o sincretismo das cozinhas das três raças (ameríndia, portuguesa e africana) - portanto, a que melhor representaria a cozinha brasileira, aquela que expressaria a identidade culinária nacional.

Na revisão do Manifesto, surpreende-nos a constatação da centralidade da temática culinária como elemento interpretativo do processo de formação e transformação da sociedade brasileira. Surpreende-nos mais ainda a constatação de que essa temática é recorrente nas quatro obras publicadas na década de 1930, as quais complementaram nossa revisão do Manifesto. Aliás, de acordo com algumas análises, parece que a temática culinária perpassa toda a trajetória intelectual de Freyre, podendo o mesmo ser considerado pioneiro da "História, Antropologia e Sociologia da Alimentação e Nutrição" no Brasil.

Ressalvando-se a distância histórico-temporal de quase um século, as profundas transformações tecnológicas, econômicas, sociais e culturais ocorridas e o intenso movimento de paradigmas, ainda assim é possível observar certa proximidade entre algumas das estratégias para a preservação da culinária regional, contidas no Manifesto, ${ }^{27}$ e aquelas propostas pela segunda edição do Guia Alimentar para a População Brasileira, centradas no paradigma contemporâneo da promoção da alimentação saudável, na valorização do consumo de alimentos in natura ou minimamente processados e na hostilidade aos produtos processados e ultraprocessados. Nessa perspectiva, identificamos a relativa "atualidade" dessa obra de Freyre. Quando o Guia Alimentar para a População Brasileira recomenda que as pessoas, sem distinção de gênero e faixa etária, desenvolvam e partilhem habilidades culinárias como estratégia para a superação de obstáculos para a garantia da alimentação saudável, ele se assemelha, atualiza e corrige o viés (preconceito/discriminação) de gênero das recomendações do Manifesto, direcionadas exclusivamente às mulheres.

Embora situados em contextos históricos distintos, no caso do Manifesto, o momento de transição entre sociedade agrário-patriarcal e sociedade capitalista urbano-industrial e, no caso do Guia, o momento de transição entre sociedade capitalista financeira e sociedade capitalista informacional, 
é possível identificar outras semelhanças entre ambos. Os dois adotam pressupostos considerados relativamente conservadores, ancorados na valorização do passado, das tradições, do habitus e na hostilidade para com as mudanças/transformações, o novo, a modernidade. No caso do Manifesto, a defesa da culinária regional agrário-patriarcal ou das tradições culinárias nordestinas e a hostilidade para com a culinária estrangeira (europeização da cozinha regional). E no caso do Guia, a valorização da culinária doméstica baseada em alimentos in natura e a hostilidade para com a industrialização de alimentos, sobretudo aqueles produtos ultraprocessados.

Outra semelhança que é possível observar em ambos os movimentos (Manifesto e Guia) é a concepção romântica de sociedade ideal. No Manifesto, o ideal de Nordeste e de preservação da cozinha nordestina parecia propor certo fechamento das fronteiras culturais da região para as ameaças externas. O Guia, centrado em paradigmas contemporâneos como aqueles da promoção da alimentação adequada e saudável; da sustentabilidade ecológica do planeta e do movimento slow food, parece propor o fechamento da culinária brasileira para algumas "benesses" do atual estágio de desenvolvimento da sociedade capitalista informacional.

Velhos e novos paradigmas acompanham as profundas transformações tecnológicas, econômicas, sociais e culturais ocorridas com o avanço da sociedade capitalista informacional. A temática central abordada neste artigo - o sistema alimentar ou culinário, a extrema velocidade em que ocorrem a produção e circulação dos alimentos (mercadorias) e das ideias sobre os alimentos (valores simbólicos) - nos faz refletir sobre as limitações e as possibilidades da defesa de argumentos em prol de uma culinária regional. Frente à nova configuração geopolítica global, quais as possibilidades e as limitações de uma culinária regional? Seria possível traçar ou impor fronteiras entre culinária regional, nacional e global? Será possível a integração global da culinária? Ou como diz certo autor, será possível a uniformização planetária da culinária ou dos hábitos alimentares?

\section{REFERÊNCIAS}

1. Fischler CA. "McDonaldização" dos costumes. In: Flandrin JL, Montanari M. História da alimentação. São Paulo: Estação Liberdade; 1998. p. 841-862.

2. Garcia RWD. Reflexos da globalização na cultura alimentar: considerações sobre as mudanças na alimentação urbana. Rev. Nutr. 2003; 16(4):483-492.

3. Vasconcelos FAG. A ciência da nutrição em trânsito: da nutrição e dietética à nutrigenômica. Rev. Nutr. 2010; 23(6):935-945.

4. Vasconcelos FAG, Batista Filho M. História do campo da alimentação e nutrição em saúde coletiva no Brasil. Ciênc. Saúde Coletiva 2011; 16(1):81-90.

5. Monteiro CA, Mondini L, Souza ALM, Popkin BM. Da desnutrição para a obesidade: a transição nutricional no Brasil. In: Monteiro CA, organizador. Velhos e novos males da saúde no Brasil: a evolução do país e de suas doenças. 2 ed. São Paulo: Hucitec/Nupens-USP; 2000. p. 247-255. 
6. Batista Filho M, Rissin A. A transição nutricional no Brasil: tendências regionais e temporais. Cad. Saúde Pública 2003; 19(Supl.1):S181-S191.

7. World Health Organization. Global strategy on diet, physical activity and health [internet]. Geneva: WHO; 2004. [acesso em: 06 fev. 2015]. Disponível em: http://www.who.int/gb/ebwha/pdf_files/ WHA57/A57_R17-en.pdf

8. Castro IRR, Souza TSN, Maldonado LA, Caniné ES, Rotenberg S, Gugelmin SA. A culinária na promoção da alimentação saudável: delineamento e experimentação de método educativo dirigido a adolescentes e a profissionais das redes de saúde e de educação. Rev. Nutr. 2007; 20(6):571-588.

9. Petrini C. Slow food: princípios da nova gastronomia. São Paulo: Senac; 2009.

10. Engler-Stringer R. Food, cooking skills, and health: a literature review. Can. J. Diet Pract. Res. 2010; 71(3):141-5.

11. Diez-Garcia RW, Castro, IRR. A culinária como objeto de estudo e de intervenção no campo da Alimentação e Nutrição. Ciênc. Saúde Coletiva 2011; 16(1):91-98.

12. Fordyce-Voorham S. Identification of essential food skills for skill-based healthful eating programs in secondary schools. J. Nutr. Educ. Behav. 2011; 43(2):116-22.

13. Hartmann C, Dohle S, Siegrist M. Importance of cooking skills for balanced food choices. Appetite 2013; 65:125-31.

14. Iacovou M, Pattieson DC, Truby H, Palermo C. Social health and nutrition impacts of community kitchens: a systematic review. Public Health Nutr. 2013; 16(3):535-43.

15. Garcia AL, Vargas E, Lam PS, Shennan DB, Smith F, Parrett A. Evaluation of a cooking skills programme in parents of young children: a longitudinal study. Public Health Nutr. 2014; 17(5):1013-21.

16. Hersch D, Perdue L, Ambroz T, Boucher JL. The impact of cooking classes on food-related preferences, attitudes, and behaviors of school-aged children: a systematic review of the evidence, 2003-2014. Prev. Chronic Dis. 2014; 11:E193.

17. Pollan M. Cozinhar: uma história natural da transformação. São Paulo: Instrínseca; 2014.

18. Reicks M, Trofholz AC, Stang JS, Laska MN. Impact of cooking and home food preparation interventions among adults: outcomes and implications for future programs. J. Nutr. Educ. Behav. 2014; 46(4):259-76.

19. Brasil. Ministério do Desenvolvimento Social e Combate à Fome. Marco de referência de educação alimentar e nutricional para as políticas públicas [Internet]. Brasília: MDC; 2012. [acesso em: 05 fev. 2015]. Disponível em: http://www.ideiasnamesa.unb.br/files/marco_EAN_visualizacao.pdf.

20. Brasil. Ministério da Saúde. Secretaria de Atenção à Saúde. Departamento de Atenção Básica. Guia alimentar para a população brasileira. 2. ed. Brasília: Ministério da Saúde, 2014.

21. Lima NT, Hochman G. Condenado pela raça, absolvido pela medicina: o Brasil descoberto pelo movimento sanitarista da Primeira República. In: Maio MC, Santos RV, organizadores. Raça, ciência e sociedade. Rio de Janeiro: Fiocruz/CCBB; 1996. p. 23-40.

22. Teixeira LA. Da raça à doença em Casa-grande e senzala. Hist. Ciên. Saúde - Manguinhos 1997; $\operatorname{IV}(2): 231-43$. 
23. Santos RV. A obra de Euclides da Cunha e os debates sobre mestiçagem no Brasil no início do século XX: os sertões e a medicina - antropologia do Museu Nacional. Hist. Ciên. Saúde - Manguinhos 1998; V(Supl.):237-53.

24. Lima NT. Um sertão chamado Brasil: intelectuais e representação geográfica da identidade nacional. Rio de Janeiro: REVAN/IUPERJ/UCAM; 1999.

25. Vasconcelos FAG. Fome, eugenia e constituição do campo da nutrição em saúde pública em Pernambuco: uma análise de Gilberto Freyre, Josué de Castro e Nelson Chaves. Hist. Ciên. SaúdeManguinhos 2001; 8(2):315-39.

26. Freyre G. Casa-grande e senzala. 34 ed. Rio de Janeiro: Record; 1998.

27. Freyre G. Manifesto regionalista de 1926. Rio de Janeiro: Ministério da Educação e Cultura. Serviço de Documentação. Os Cadernos de Cultura [Internet]. 1955. [acesso em: 18 dez. 2014]. Disponível: <http://icaadocs.mfah.org/icaadocs/THEARCHIVE/FullRecord/tabid/88/doc/1074787/language/ en-US/Default.aspx>.

28. Amaral Jr A. Sensualismo e consciência regional: o nordeste freyriano. Raízes [Internet] 2002; 21(02):227-232. [acesso em: 20 dez 2014]. Disponível em: http://www.ufcg.edu.br/ raizes/artigos/ Artigo_71.pdf.

29. Santos R. Cultura e tradição em Gilberto Freyre: esboço de interpretação do Manifesto regionalista. Soc. Cult. 2011; 14(2):399-408.

30. Mascaro LP. Similaridades entre regionalismo e antropofagia: nacionalismo - internacionalismo regionalismo. Mneme. Revista Virtual de Humanidades [Internet] 2004; (10):43-59. [acesso em: 21 dez 2014]. Disponível em: http://www.periodicos.ufrn.br/mneme/article/view/199/183.

31. Freyre G. Açúcar: uma sociologia do doce, com receitas de bolos e doces do Nordeste do Brasil. 5 ed. São Paulo: Global; 2007.

32. Freyre G. Nordeste: aspectos da influência da cana sobre a vida e a paisagem do Nordeste do Brasil. 7 ed. São Paulo: Global; 2004.

33. Calazans R. Ambivalências: o nordeste nas obras de Gilberto Freyre e Celso Furtado. Rev. Bras. Ci. Soc. 2007; 22(64):75-80.

34. Castro J. Geografia da fome (o dilema brasileiro: pão ou aço). 10 ed. Rio de Janeiro: Antares Achiamé; 1980.

35. Hernández JC, Arnáiz MG. Alimentación y cultura: perspectivas antropológicas. Barcelona: Editorial Ariel; 2005.

36. Poulain JP, Proença RPC. O espaço social alimentar: um instrumento para o estudo dos modelos alimentares. Rev. Nutr. 2003; 16(3):245-256.

37. Bourdieu P. O poder simbólico. Rio de Janeiro: Bertrand Brasil; 1998.

38. Bourdieu P. Para uma sociologia da ciência. Lisboa: Biblioteca 70; 2008.

39. Kuhn TS. O caminho desde a estrutura. São Paulo: UNESP; 2006.

40. Castells M. A sociedade em rede. A era da informação: economia, sociedade e cultura. São Paulo: Paz e Terra; 1999. 
41. Freyre G. Sobrados e Mucambos. 12 ed. Rio de Janeiro: Record; 2000.

42. Vasconcelos FAG. Josué de Castro e a geografia da fome no Brasil. Cad. Saúde Pública 2008; 24(11):2710-2717.

43. Santos RL. Algumas considerações sobre o negro e o índio no Casa Grande e Senzala de Gilberto Freyre. Rev. Espaço Acadêmico [Internet] 2012; 12(138):113-120. [acesso em: 18 dez. 2014]. Disponível: http://periodicos.uem.br/ojs/index.php/EspacoAcademico/article/view/17835/9958.

44. Cascudo LC. História da alimentação no Brasil. 4 ed. São Paulo: Global; 2011.

45. Tempass MC. Os grupos indígenas e os doces brasileiros. Espaço Ameríndio [Internet] 2008; 2(2):98114. [acesso em: 19 dez 2014]. Disponível: http://seer.ufrgs.br/index.php/EspacoAmerindio/article/ view/7201/4553.

Recebido: $11 / 2 / 2015$

Aceito: 18/9/2015 
